Рецензия / Review

УдК 55:[004.78:002]:528.94

DOI: 10.18470/1992-1098-2020-4-177-183

Геоинформационное картографирование в урбоэкологии (рецензия на монографии: Оценка и геоинформационное картографирование медико-экологической ситуации на территории города Воронежа: Сборник научных статей / Под общ. ред. С.А. Куролапа и О.В. Клепикова. Воронеж: Цифровая полиграфия, 2019. 219 с.; Экологические риски территорий интенсивного техногенного освоения / С.А. Куролап, О.В. Клепиков, Т.И. Прожорина и др. / Под общ. ред. С.А. Куролапа и О.В. Клепикова. Воронеж: Цифровая полиграфия, 2019. 191 с.)

Наталья В. Костина ${ }^{1}$, Наталья В. Лазарева ${ }^{2}$, Геннадий С. Розенберг ${ }^{1}$

${ }^{1}$ Институт экологии Волжского бассейна РАН, Тольятти, Россия

${ }^{2}$ Самарский государственный экономический университет, Самара, Россия

\begin{abstract}
Резюме
Рецензия на сборник научных статей «Оценка и геоинформационное картографирование медико-экологической ситуации на территории города Воронежа» (под общ. ред. С.А. Куролапа и О.В. Клепикова. Воронеж: Цифровая полиграфия, 2019. 219 с.) и монографию «Экологические риски территорий интенсивного техногенного освоения» (С.А. Куролап, О.В. Клепиков, Т.И. Прожорина и др. / Под общ. ред. С.А. Куролапа и О.В. Клепикова. Воронеж: Цифровая полиграфия, 2019. 191 с.) написана в ходе самоизоляции и удалённого доступа к работе авторов в связи с пандемией коронавируса COVID-19.
\end{abstract}

\section{Контактное лицо}

Геннадий С. Розенберг, член-корреспондент РАН, доктор биологических наук, главный научный сотрудник, Институт экологии Волжского бассейна РАН; 445003 Россия, Самарская обл., г. Тольятти, ул. Комзина, 10.

Тел. +79036879448

Email genarozenberg@yandex.ru

ORCID https://orcid.org/0000-0002-8820-4459

\begin{abstract}
Формат цитирования
Костина Н.В., Лазарева Н.В., Розенберг Г.С. Геоинформационное картографирование в урбоэкологии (рецензия на монографии: Оценка и геоинформационное картографирование медикоэкологической ситуации на территории города Воронежа: Сборник научных статей / Под общ. ред. С.А. Куролапа и О.В. Клепикова. Воронеж: Цифровая полиграфия, 2019. 219 с.; Экологические риски территорий интенсивного техногенного освоения / С.А. Куролап, О.В. Клепиков, Т.И. Прожорина и др. / Под общ. ред. С.А. Куролапа и О.В. Клепикова. Воронеж: Цифровая полиграфия, 2019. 191 с.) // Юг России: экология, развитие. 2020. T.15, N 4. C. 177-183. DOI: 10.18470/1992-1098-2020-4-177183
\end{abstract}

Получена 22 июля 2020 г. Принята 25 августа 2020 г.

(C) 2020 Авторы. Юг России: экология, развитие. Это статья открытого доступа в соответствии с условиями Сreative Соmmоns Attribution License, которая разрешает использование, распространение и воспроизведение на любом носителе при условии правильного цитирования оригинальной работы. 


\title{
Geoinformation mapping in urban ecology. Review of: "Assessment and geoinformation mapping of the medical and environmental situation in the city of Voronezh: Collection of scientific articles" / Under general editorship of S.A. Kurolap and O.V. Klepikov. Voronezh: Digital printing, 2019. 219 p. and of "Environmental risks of regions of intensive technogenic development" / S.A. Kurolap, O.V. Klepikov, T.I. Prozhorina et al / Under general editorship of S.A. Kurolap and O.V. Klepikov. Voronezh: Digital printing, 2019. 191 p.
}

Natalia V. Kostina ${ }^{1}$, Natalia V. Lazareva ${ }^{2}$, Gennady S. Rosenberg ${ }^{1}$ ${ }^{1}$ Institute of Ecology of the Volga Basin, Russian Academy of Sciences, Togliatti, Russia

${ }^{2}$ Samara State University of Economics, Samara, Russia

\begin{abstract}
Review of the collection of scientific articles "Assessment and geoinformation mapping of the medical and environmental situation in the city of Voronezh" (under the general editorship of S. A. Kurolap and O. Klepikov. Voronezh: Digital Printing, 2019, 219 p.) and of the monograph "Environmental risks of territories of intensive technogenic development" (S.A. Kurolap, O.V. Klepikov, T.I. Prozhorina et al / Under the general editorship of S.A. Kurolap and O.V. Klepikov). Voronezh: Digital printing, 2019. 191 p. The review was written during the period of self-isolation and remote access to the authors' work associated with the COVID-19 pandemic.
\end{abstract}

Principal contact

Gennady S. Rozenberg, Corresponding Member, Russian Academy of Sciences, Doctor of Biological Sciences, Chief Researcher, Institute of Ecology of the Volga River Basin, Russian Academy of Sciences, 10 Komzin St, Togliatti, Samara region, Russia 445003.

Tel. +79036879448

Email genarozenberg@yandex.ru

ORCID https://orcid.org/0000-0002-8820-4459

\section{How to cite this article}

Kostina N.V., Lazareva N.V., Rosenberg G.S. Geoinformation mapping in urban ecology. Review. South of Russia: ecology, development. 2020, vol. 15, no. 4, pp. 177-183. (In Russian) DOI: 10.18470/1992-1098-2020-4-177-183 
Результаты исследований, изложенные в рецензируемых сборнике и монографии, выполнены в рамках грантов Русского географического общества и Российского фонда фундаментальных исследований. Уже сам факт того, что эти работы были поддержаны столь уважаемыми (но к сожалению для нашей страны, весьма немногочисленными) фондами, свидетельствует о том, что геоинформационно-аналитические разработки в области оценки рисков для здоровья населения весьма актуальны и перспективны. Наш опыт проведения сходного рода исследований (назовем здесь только некоторые брошюры и монографии [1-9], позволяет нам критически рассмотреть эти труды, вышедшие под совместной редакцией профессоров, доктора географических наук С.А. Куролапа и доктора биологических наук О.В. Клепикова.

Сборник работ, как это и следует из его названия, посвящен оценке медико-экологической ситуации в городе Воронеже - одном из крупнейших промышленных центров Черноземья. Современные промышленно развитые города - центры острейших экологических проблем, что требует постоянного совершенствования систем регионального геоэкологического мониторинга с систематическим наблюдением за состоянием различных компонентов среды обитания и общественного здоровья.

Открывает сборник статья С.А. Куролапа с соавторами «Геоинформационное картографирование состояния окружающей среды промышленного города (опыт практической реализации на примере города Воронежа)» (с. 6-54); это самая крупная статья сборника, около четверти его объема. Фактически, авторы делают презентацию электронного «Медикоэкологического атласа города Воронежа» (35 карт масштабом $1: 25$ 000) [10]. Атлас включает следующие разделы: состояние окружающей среды (экологический фон: параметры техногенного воздействия и загрязнения атмосферы, почвы, снежного покрова; состояние родников; радиационный фон; фитотоксические эффекты; состояние биоты); состояние здоровья населения (по основным социально значимым классам заболеваний отдельно для взрослого и детского населения по территориям обслуживания поликлиник города); оценка экологического риска для здоровья населения (рисков, связанных с микроклиматическими условиями, промышленно-транспортным воздействием и техногенным загрязнением городской среды). Каждый из этих блоков подробно прокомментирован и проиллюстрирован картосхемами распределения загрязняющих веществ по территории города.

В качестве примера, остановимся на разделе «Состояние водных объектов: размещение и гидрохимическая оценка качества воды родников» (с. 28-36). Родники вообще редко попадают в «поле зрения» экологов (именно, в контексте "водных ресурсов" территории); даже уже поэтому работу по инвентаризации родников г. Воронежа и налаживанию дальнейшей системы мониторинга гидрохимического качества родниковой воды, следует только приветствовать. Естественно, если к этим работам будут подключены микро- и гидробиологи, эффективность оценки существенно повысится.
Завершает статью раздел «Интегральная медико-экологическая оценка» (с. 49-54). Такая оценка получена авторами работы после "обобщения закономерностей статистических связей в системе "окружающая среда - здоровье населения" с применением современных эколого-геохимических, вероятностностатистических и геоинформационных методов исследования» (с. 49). Здесь следует сделать несколько замечаний. Прежде всего, используемый для анализа показатель канцерогенного риска по своей сути мало чем отличается от, например, ИзВ (индекса загрязненности воды) или ИЗА (индекса загрязнения атмосферы); разница лишь в том, что реальная концентрация вещества $\boldsymbol{i}$ в пробе нормируется для Из величиной пДК для канцерогенного риска - величиной реферативной (безопасной) концентрации. Как и для ИЗ, анализ обычно проводится на основе "детального исследования ограниченного числа приоритетных веществ, которые наилучшим образом (кто это оценивает? - Авторы) характеризуют реальный риск для здоровья населения, проживающего на исследуемой территории» [11]. В этой ситуации возрастает шанс пропустить важное для анализа вещество. Вызывает сомнение и "суммируемость рисков» при расчете индекса суммарного эффекта (критериев приемлемости), - авторы исключают возможные эффекты взаимодействия и загрязняющих веществ, и канцерогенных рисков. Наконец, отсутствуют микробиологические показатели, что также (как и для Из) снижает качество обобщенных индексов.

В статье Е.М. Студениконой с соавторами «Геоинформационные системы в оценке уровня заболеваемости городского населения массовыми неинфекционными заболеваниями» (с. 55-83) рассматривается раздел базы данных по заболеваемости населения для «Медико-экологического атласа города Воронежа». Выявлены территории риска и даны ареалы заболеваемости населения (две группы: до 14 лет и старше 18 лет) по основным классам болезней (общая заболеваемость, болезни органов дыхания, пищеварения, мочеполовой системы, болезней крови, а также врожденных аномалий детского населения и злокачественных новообразований у взрослого). Авторы делают справедливый вывод о том, что «анализ многолетней информации об уровнях заболеваемости населения свидетельствует о многогранности проблемы сохранения здоровья жителей промышленно-развитого города» (с. 82).

Остальные статьи сборника посвящены более частным аспектам геоинформационного картографирования. Так, в статье А.А. Куролапа с соавторами «Экологическая оценка параметров автотранспортного шума, микроклимата и техногенного загрязнения атмосферы города Воронежа» (с. 83-94) дано экологомикроклиматическое зонирование территории города (рисунок на с. 91). Несомненный интерес представляет изучение воздействия на здоровье человека достаточно редко исследуемого фактора шумового загрязнения. Было бы интересным, провести сравнение результатов по городу Воронежу и городу Тольятти [12; 13]. Вопросам естественного самоочищения атмосферного воздуха в городах (планировочные решения, учет рельефа, зеленые зоны и другие элементы природного каркаса) 
посвящена статья С.А. Епринцева и С.В. Шекоян «Микроклимат и природный каркас городской среды как факторы формирования зон экологического риска (на примере города Воронежа)» (с. 94-105).

Статьи Ю.С. Калашникова и О.В. Клепикова «Анализ экологических рисков, связанных с техногенной нагрузкой и рекреационным воздействием на реку Дон в пределах Воронежской городской агломерации» (c. 105-130), Т.И. Прожориной и О.А. Гребенниковой «Экологические проблемы утилизации загрязненного снега, вывозимого с территории города Воронежа» (с. 130-138) и Т.И. Прожориной с соавторами «Исследование влияния несанкционированной снегосвалки на экосистему территории Ботанического сада Воронежского университета» (с. 139-146), если можно так обобщить, посвящены "водному блоку» базы данных. Здесь внимание привлекают данные по органолептическим, санитарно-гигиеническим и микробиологическим показателям качества воды в р. Дон (особенно, в зонах рекреации), которые позволили авторам сделать вывод о «существенном ухудшении показателей качества воды оцениваемого водного объекта» (с. 129). Негативную картину демонстрирует и анализ снега на городской снегосвалке (взвешенные вещества превышают фоновые значения в 30 раз, содержание ионов $\mathrm{Cl}$ - в 34 раза, Са и $\mathrm{Mg}$ - в 5 раз); еще хуже результаты для несанкционированной свалки около Ботанического сада ВГУ (взвешенные вещества превышают фоновые значения почти в 3000 раз, содержание ионов Сl - в 300 раз, общая жесткость воды - в 18 раз). Правда, вывод, который делают авторы из этой ситуации, выглядит как-то беспомощным: «если не предпринять срочные меры по ликвидации незаконной снегосвалки, то в ближайшее время после весеннего снеготаяния засоленные талые воды могут нагнести непоправимый вред уникальному природному комплексу...».

Статья М.А. Клевцовой и Е.А. Добровой «Биоиндикационная оценка пылеулавливающей способности листовых пластинок тополя итальянского в условиях техногенного загрязнения городской среды» (с. 147160) посвящена анализу морфометрических параметров листовых пластин тополя (Populus italica) и накоплению пыли на ассимилирующих органах. За период 2016-2018 гг. запыленность атмосферного воздуха (по минимальным значениям) выросла почти в 2 раза, по максимальным - на $50 \%$.

«Почвенному блоку» базы данных посвящены статьи Н.В. Кавериной «Городские техногенные аномалии: загрязнение нефтепродуктами и легкорастворимыми солями поверхностного горизонта почв города Воронежа» (с. 161-173) и «Полициклические ароматические углеводороды в почвах функциональных зон города Воронежа» (с. 174-185) и статья Л.О. Середа, С.А. Куролап «Токсилогический анализ почвенного покрова города Воронежа» (с. 185-195). Результаты исследований свидетельствуют о том, что городские почвы серьёзно загрязнены, а для «почвенных образцов, отобранных в промышленной зоне, характерно в основном превышение критерия токсичности, что составляет в среднем 30-50\%» (с. 191).

Завершают сборник две статьи теоретикометодического плана: С.А. Епринцев, С.В. Шекоян «Геоинформационно-экологический мониторинг террито- рии города Воронежа как средство обеспечения экологической безопасности городской среды» (с. 196-206) и С.А. Куролап с соавторами «Геоинформационное обеспечение создания системы медико-экологического мониторинга крупного промышленного центра: методические принципы и рекомендации» (с. 206-216). Развитие представлений о средствах и способах решения информационных задач привели к появлению геоинформационных (ГИС) и экоинформационных систем (ЭИС), которые обеспечивают хранение и оперативный доступ к совокупности данных и знаний об экосистемах, о взаимодействии природы и общества. С.А.Куролап с коллегами подробно комментирует 9 основных принципов создания ГИС.

Хотелось бы заметить, что геоинформатика поражает и покоряет немыслимыми массивами данных, которыми она играючи оперирует, однозначностью и воспроизводимостью получаемых результатов. При создании "классических" ГИС активно пропагандируются современные методы географического мониторинга - аэрокосмический, подспутниковый и т. д. Однако генерирование новой информации, свойственное ГИС-технологиям, содержательно и интересно только тогда, когда кто-то извне, представитель иной сферы знания или же целая другая наука «вкладывает» в уста геоинформатики содержательное понимание определенной задачи (необходима база знаний). При этом, ни в коей мере не отрицая необходимости и желательности проведения специальных (в том числе и дистанционных) видов исследований, следует иметь в виду, что общие затраты на создание такого рода ГИС для достаточно скромного по размерам региона становятся огромными.

В то же время в территориальных органах охраны природы, учебных заведениях, отраслевых институтах и специализированных краеведческих организациях накоплен богатый материал по различным аспектам исследований в области экономики, природопользования и медицины региона. В подавляющем большинстве случаев этот материал никак серьезно не обрабатывался и хранится в виде полузабытой «бумажной субстанции». Не исключено, что собранная статистическими методами в "административном аспекте», эта информация «зашумлена» и даже тенденциозна, а её пространственная привязка нередко оказывается весьма размытой. Тем не менее, при разумном подходе к её обработке и интерпретации эти данные становятся не только важным, но и определяющим звеном информационной модели территории. Во всяком случае, вывод о необходимости проведения комплекса дорогостоящих дистанционных исследований разумно делать лишь после обобщения всего багажа уже имеющейся эколого-экономической информации. Именно в этом смысле геоинформатика тесно смыкается с экоинформатикой, о чем свидетельствует наш опыт создания эИС разного масштаба [7; 14]. Пожертвовав географической эстетичностью, которая по отношению к пространственно размытым («грязным») данным вряд ли оправдана необходимостью, такая ЭИС приобретает не менее привлекательные качества: дешевизна, экономичность в ресурсах, простота в освоении, эксплуатации и интерпретации выходных данных. Более того, она позволяет строить статистические модели разной 
сложности для оценки связей и прогнозирования в системе «окружающая среда - здоровье населения».

Завершая обзор этого интересного сборника, отметим, что и авторы, и мы вместе с ними находимся лишь в начале пути. Вот что пишут в своем обзоре об анализе рисков С.Г. Харченко и Е.Ю. Дорохина [15]: «Анализируя тенденции и перспективы анализа риска окружающей среды в России, необходимо отметить, что работы в области безопасности и анализа риска окружающей среды в России были начаты по инициативе академика В.А. Легасова еще в начале 80-х годов. Но только после Чернобыльской аварии это направление получило возможность развиваться, хотя и не так стремительно, как это происходило в США, Канаде, странах Евросоюза, Японии и Австралии. К сожалению, до сих пор законодательная и нормативная база в России построена не на основе концепции риска, а на основе ПДВ и ПДК, и само понятие риска упоминается только в одном из более 50 законов, посвященных безопасности, - в Федеральном Законе "О техническом регулировании» 2002 г. И вообще, ни в одном из них не допускается количественная оценка безопасности, а количественная оценка опасности производится на основе предельно допустимых концентраций вредных веществ, не позволяющая выполнять интегральную оценку опасности. Однако концептуально и методологически анализ риска до сих пор не является научной основой ни нашего законодательства, ни практической деятельности, в отличие от вышеупомянутых развитых стран. Хотя в отечественной науке достигнуты заметные результаты в этой области».

Несколько слов о второй работе - коллективной (14 авторов) монографии «Экологические риски территорий интенсивного техногенного освоения». В книге 6 глав, «Введение» и «Заключение». Уже во «Введении» авторы постулируют, что «методология исследований базируется на комплексных экспедиционных, лабораторно-инструментальных эколого-геохимических, радиоэкологических, биоиндикационных и геоинформационно-аналитических исследованиях» (с. 5).

В первой главе «Интегральная оценка экологического состояния территорий интенсивного техногенного воздействия: подходы и опыт реализации» (с. 656) представлены обсуждаются теоретикометодологические основы оценки и мониторинга экологических рисков территорий, находящихся под интенсивной техногенной нагрузкой. Не вдаваясь здесь в историю вопроса о соотношении здоровья и качества окружающей нас природы (согласно данным Всемирной организации здравоохранения [ВО3], вклад состояния окружающей среды в здоровье населения в среднем составляет 18-22\%; при этом наибольший вклад [50-52\%] вносит образ жизни [национальные особенности, привычки и т. п.]; вклад биологического фактора [генетика] оценивается в 20-22\%, а роль медицины - в 7-12\%; аналогичную схему приводят и авторы на с. 10), заметим, что уже древние греки чувствовали и понимали эту связь; древнегреческий целитель, врач («отец медицины»), философ Гиппократ (ок. 460 г. до н. э. 370 г. до н. э.) писал: «Болезни излечивает природа, врач только помогает ей».

В главе обсуждаются основные критерии и методы оценки экологических рисков для здоровья насе- ления, методологические основы создания региональных систем экологического мониторинга техногенно загрязнённых территорий, качественно новая информация о состоянии объектов окружающей среды промышленно развитого города (в основном, на примере г. Воронежа) и связанного с этим риском для здоровья населения, полученной на основе технологий геоинформационных систем.

Вторая глава «Оценка экологических рисков, связанных с качеством хозяйственно-питьевого водоснабжения урбанизированных и сельских территорий» (c. 57-73) посвящена анализу состояния централизованного хозяйственно-питьевого водоснабжения малых городов и поселков городского типа Воронежской области (Анна, Богучар, Лиски, Новохоперск и Россошь). Этот анализ показал крайне неудовлетворительное состояние качества питьевой воды (только 16\% проб оказались соответствующими нормативам). Так, для Новохоперска характерна повышенная жесткость воды, превышение нормативов по хлоридам и нитратам.

Главы 3-5 («Оценка экологического состояния водных объектов и городской среды методами биоиндикации и биотестирования» [с. 74-116], «Радиоэкологические исследования на территории города Воронежа» [c. 117-125] и «Экогеохимия урбанизированных территорий» [с. 126-173]) во многом перекликаются с уже рассмотренным выше сборником работ «Оценка и геоинформационное картографирование медикоэкологической ситуации на территории города Воронежа». Здесь особо выделим небольшую по объему главу 4, в которой представлены результаты наблюдений за гамма-излучением на открытой местности городского пространства (70 точек). Было установлено, что мощность эквивалентной дозы гамма-излучения (гамма-фона) на территории города Воронежа не превышает допустимых значений, но максимальные уровни гамма-фона были отмечены в тех местах, где для благоустройства использовался обработанный гранит.

Завершает монографию глава 6 «Геоинформационное картографирование селитебно-промышленных территорий: опыт практической реализации» (с. 174-188). Эта глава - явно методического плана и её место должно было бы быть в начале монографии (сразу после первой главы). Интерес представляет сравнение двух методов интерполяции данных на геоинформационных картах: методом обратных взвешенных расстояний (Inverse Distance Weighting - IDW) и нерегулярной сети треугольников (Triangulated Irregular Network - TIN); предпочтение отдано первому методу IDW. Часть представленных результатов носит частный («программистский») характер - выбор тех или иных «штатных» инструментов ГИС Maplnfo, задание «горячих клавиш», обоснование необходимости использования специального языка программирования MapBasic и пр. Все эти приемы позволили произвести «оценку качества окружающей среды по критерию риска возникновения у населения экологически-обусловленных заболеваний» (с. 183) с существенной экономией времени расчетов. К этой главе рецензируемой монографии можно сделать то же замечание, что было сделано выше, при рецензировании сборника: в таком теоретически-методическом разделе хотелось бы видеть предложения по синтезу статистических моделей разной 
сложности для оценки связей и прогнозирования в системе «окружающая среда - здоровье населения».

Фундаментальной основой обеспечения устойчивого развития социо-эколого-экономических систем регионов России является оптимизация разного рода рисков (социальных, экологических, экономических [финансовых] и пр.). В большинстве регионов высокий инвестиционный потенциал сочетается с высоким уровнем социально-экологических рисков [16]. Однако в настоящее время, как отмечено рядом исследователей [17], «практически отсутствуют методы количественной оценки техногенных социальноэкологических рисков причинения вреда здоровью населения под воздействием вредных факторов окружающей среды. Существующие методы основаны на масштабных долгосрочных и дорогостоящих медикобиологических исследованиях и не учитывают специфические для конкретного региона факторы». Прорецензированные работы вносят определенный вклад в заполнение такого рода «лакун» для объективизации оценок экологических рисков и создания эффективного геоинформационно-картографического инструментария при анализе медико-экологических ситуаций на территориях разного масштаба и разной антропогенной нагрузки.

\section{БИБЛИОГРАФИЧЕСКИЙ СПИСОК}

1. Краснощеков Г.П., Розенберг Г.С. Здоровье населения как критерий оценки качества среды. Тольятти: ИЭВБ РАН, 1994. 53 с.

2. Шапеева Е.В., Юрицына Н.А., Лифиренко Н.Г., Юнина В.П., Афанасьева Н.В. Эколого-информационные системы разных масштабов для комплексной оценки состояния природной среды в регионах с интенсивной антропогенной нагрузкой (город, область, Волжский бассейн). Тольятти: ИЭВБ РАН, 1994. 53 с.

3. Розенберг Г.С., Краснощеков Г.П., Сульдимиров Г.К. Экологические проблемы города Тольятти

(Территориальная комплексная схема охраны окружающей среды). Тольятти: ИЭВБ РАН, 1995. 222 с. 4. Розенберг Г.С., Рянский Ф.Н., Лазарева Н.В., Саксонов С.В., Симонов Ю.В., Хасаев Г.Р. Общая и прикладная экология: учеб. пособие. Самара; Тольятти: Изд-во Самар. гос. экон. ун-та, 2016. 452 с. URL:

http://www.ievbras.ru/books/books.html (дата обращения: 24.03.2020)

5. Горелик Д.О., Ишанин Г.Г., Конопелько Л.А., Хворов Г.В., Розенберг Г.С. и др. Экологический атлас г. Тольятти. СПб.: НПО "Мониторинг", 1996. 9 карт масштаба 1 : 40000.

6. Коломыц Э.Г., Розенберг Г.С., Глебова О.В., Сурова Н.А., Сидоренко М.В., Юнина В.П. Природный комплекс большого города: ландшафтно-экологический анализ. М.: Наука, 2000. 286 с.

7. Костина Н.B. REGION: экспертная система управления биоресурсами. Тольятти: Самар. НЦ РАН, 2005. 132 c.

8. Костина Н.В. Анализ состояния и сценарии развития социо-эколого-экономических систем территорий разного масштаба с помощью экспертной информационной системы REGION. Тольятти: Кассандра, 2015. 200 с
9. Зибарев А.Г., Розенберг Г.С., Саксонов С.В. и др. Институт экологии Волжского бассейна РАН и город Тольятти. Экологические инновации для устойчивого развития города. Аналитический доклад. Тольятти: Кассандра, 2012. 87 с.

10. Медико-экологического атлас города Воронежа (35 карт масштабом 1 : 25 000). URL:

http://www.geogr.vsu.ru/atlas.htm (дата обращения: 08.07.2020)

11. Степанова Н.В., Валеева Э.Р., Фомина С.Ф. Оценка канцерогенного риска для здоровья населения при воздействии химических веществ. Казань: К(П)ФУ; ИФМиБ. 2016. 128 с.

12. Васильев А.В., Лифиренко Н.Г., Костина Н.В., Розенберг Г.С. Шумовое загрязнение и его оценка как фактора риска заболеваемости населения // Труды X Всероссийского конгресса «Экология и здоровье человека», 11-13 октября 2005 г. Самара: Самар. обл. Дом науки и техн., 2005. С. 49-51.

13. Васильев А.В., Розенберг Г.С. Мониторинг акустического загрязнения селитебной территории г. Тольятти и оценка его влияния на здоровье населения // Безопасность в техносфере. 2007. N 3. C. 9-12.

14. Розенберг Г.С. Волжский бассейн: на пути к устойчивому развитию. Тольятти: ИЭВБ РАН; Кассандра, 2009. 477 c.

15. Харченко С.Г., Дорохина Е.Ю. Анализ рисков окружающей среды // Вопросы анализа риска. 2009. N 1-2. С. 92-105.

16. Розенберг Г.С., Зибарев А.Г., Костина Н.В., Кудинова Г.Э., Розенберг А.Г. Оценки рисков и ущербов как инструмент социальной экологии // Биосфера. 2019. Т. 11. N 2. С. $75-86$

17. Бразговка О.В., Сугак Е.В. Интеллектуальный анализ социально-экологических рисков населения промышленного региона // Фундаментальные проблемы науки: сб. статей Междунар. науч.-практ. конф. (20 июня 2017 г., Казань). Часть 4. Уфа: АЭТЕРНА; 2017. С. 212-214.

\section{REFERENCES}

1. Krasnoshchekov G.P., Rozenberg G.S. Zdorov'e naseleniya kak kriterii otsenki kachestva sredy [Public Health as a Criterion for Assessing the Quality of the Environment]. Tol'yatti, Institute of Ecology of the Volga Basin RAS Publ., 1994, 53 p. (In Russian)

2. Shapeeva E.V., Yuritsyna N.A., Lifirenko N.G., Yunina V.P., Afanas'eva N.V. Ekologo-informatsionnye sistemy raznykh masshtabov dlya kompleksnoi otsenki sostoyaniya prirodnoi sredy $v$ regionakh s intensivnoi antropogennoi nagruzkoi (gorod, oblast', Volzhskii bassein) [Ecological Information Systems of Various Scales for a Comprehensive Assessment of the State of the Natural Environment in Regions with Intense Anthropogenic Pressure (City, Region, Volga River Basin)]. Tol'yatti, Institute of Ecology of the Volga Basin RAS Publ., 1994, 53 p. (In Russian)

3. Rozenberg G.S., Krasnoshchekov G.P., Sul'dimirov G.K. Ekologicheskie problemy goroda Tol'yatti (Territorial'naya kompleksnaya skhema okhrany okruzhayushchei sredy) [Ecological Problems of the City of Togliatti (Territorial Integrated Scheme of Environmental Protection)]. Tol'yatti, Institute of Ecology of the Volga Basin RAS Publ., 1995, 222 p. (In Russian) 
4. Rozenberg G.S., Ryanskiy F.N., Lazareva N.V., Saksonov S.V., Simonov Yu.V., Khasaev G.R. Obshchaya i prikladnaya ekologiya [General and Applied Ecology]. Samara, Tol'yatti, SSEU Publ., 2016, 452 p. (In Russian) Available at: http://www.ievbras.ru/books/books.html (accessed 24.03.2020)

5. Gorelik D.O., Ishanin G.G., Konopel'ko L.A., Hvorov G.V., Rozenberg G.S. et al. Ekologicheskii atlas g. Tol'yatti [Ecological Atlas of Togliatti]. SPb., NPO "Monitoring" Publ., 1996. (In Russian)

6. Kolomyts E.G., Rozenberg G.S., Glebova O.V., Surova N.A., Sidorenko M.V., Yunina V.P. Prirodnyi kompleks bol'shogo goroda: landshaftno-ekologicheskii analiz [Natural Complex of a Big City: Landscape-Ecological Analysis]. Moscow, Nauka Publ., 2000, 286 p. (In Russian)

7. Kostina N.V. REGION: ekspertnaya sistema upravleniya bioresursami [REGION: an Expert Bio-Resource Management System]. Tol'yatti, SSC RAS Publ., 2005, 132 p. (In Russian)

8. Kostina N.V. Analiz sostoyaniya i stsenarii razvitiya sotsio-ekologo-ekonomicheskikh sistem territorii raznogo masshtaba s pomoshch'yu ekspertnoi informatsionnoi sistemy REGION [Analysis of the State and Scenarios for the Development of Socio-Ecological-Economic Systems of Territories of Different Scales Using the Expert Information System REGION]. Tol'yatti, Kassandra Publ., 2015, 200 p. (In Russian)

9. Zibarev A.G., Rozenberg G.S., Saksonov S.V. et al. Institut ekologii Volzhskogo basseina RAN i gorod Tol'yatti. Ekologicheskie innovatsii dlya ustoichivogo razvitiya goroda. Analiticheskii doklad [Institute of Ecology of the Volga Basin of the Russian Academy of Sciences and the city of Togliatti. Environmental Innovation for Sustainable City Development. Analytical Report]. Tol'yatti, Kassandra Publ., 2012, 87 p. (In Russian)

10. Mediko-ekologicheskogo atlas goroda Voronezha (35 kart masshtabom $1: 25$ 000) [Medical and ecological atlas of the city of Voronezh (35 maps in scale 1: 25,000$)$ ]. URL:

\section{КРИТЕРИИ АВТОРСТВА}

Наталья В. Костина, Наталья В. Лазарева, Геннадий С. Розенберг подготовили и написали рецензию. Авторы несут ответственность при обнаружении плагиата, самоплагиата или других неэтических проблем.

\section{КОНФЛИКТ ИНТЕРЕСОВ}

Авторы заявляют об отсутствии конфликта интересов. http://www.geogr.vsu.ru/atlas.htm (accessed 08.07.2020). (In Russian)

11. Stepanova N.V., Valeeva E.R., Fomina S.F. Otsenka kantserogennogo riska dlya zdorov'ya naseleniya pri vozdeistvii khimicheskikh veshchestv [Assessment of Carcinogenic Risk to Public Health When Exposed to Chemicals]. Kazan', K(V)FU, IFMB Publ., 2016, 128 p. (In Russian) 12. Vasil'ev A.V., Lifirenko N.G., Kostina N.V., Rozenberg G.S. Shumovoe zagryaznenie i ego otsenka kak faktora riska zabolevaemosti naseleniya [Noise Pollution and its Assessment as a Risk Factor for Morbidity in the Population]. Trudy X Vserossiiskogo kongressa "Ekologiya i zdorov'e cheloveka», Samara, 11-13 oktyabrya 2005 [Proceedings of X All-Russian Congress "Ecology and Human Health", Samara, 11-13 October 2005]. Samara, 2005, pp. 49-51. (In Russian)

13. Vasil'ev A.V., Rozenberg G.S. Monitoring of acoustic pollution of the residential area of Togliatti and assessment of its impact on public health. Bezopasnost' v tekhnosfere [Safety in the Technosphere]. 2007, no. 3, pp. 9-12. (In Russian)

14. Rozenberg G.S. Volzhskii bassein: na puti $k$ ustoichivomu razvitiyu [Volga River Basin: Towards Sustainable Development]. Tol'yatti, IEVB RAN, Kassandra Publ., 2009, 477 p. (In Russian)

15. Kharchenko S.G., Dorokhina E.Yu. Analysis of environmental risks. Voprosy analiza riska [Issues of Risk Analysis]. 2009, no. 1-2, pp. 92-105. (In Russian)

16. Rozenberg G.S., Zibarev A.G., Kostina N.V., Kudinova G.E., Rozenberg A.G. Assessment of risks and damages as a tool of social ecology. Biosfera [Biosphere]. 2019, vol. 11, no. 2, pp. 75-86. (In Russian)

17. Brazgovka O.V., Sugak E.V. [Intellectual analysis of social and environmental risks of the population of an industrial region]. In: Fundamental'nye problemy nauki [Fundamental Problems of Science]. Ufa, AETERNA Publ., 2017, pp. 212-214. (In Russian)

\section{AUTHOR CONTRIBUTIONS}

Gennady S. Rozenberg, Natalia V. Kostina and Natalia V. Lazareva prepared and wrote the review. All authors are equally responsible for plagiarism, self-plagiarism and other ethical transgressions.

\section{NO CONFLICT OF INTEREST DECLARATION}

The authors declare no conflict of interest.

\section{ORCID}

Наталья В. Костина / Natalia V. Kostina https://orcid.org/0000-0002-8666-2130

Наталья В. Лазарева / Natalia V. Lazareva https://orcid.org/0000-0001-6528-1585

Геннадий С. Розенберг / Gennady S. Rozenberg https://orcid.org/0000-0002-8820-4459 